\title{
TU/e ENHHONE

\section{Generation of local magnetic fields at megahertz rates for the study of domain wall propagation in magnetic nanowires}

\section{Citation for published version (APA):}

Bergman, B., Moriya, R., Hayashi, M., Thomas, L., Tyberg, C., Lu, Y., Joseph, E., Rothwell, M-B., Hummel, J., Gallagher, W. J., Koopmans, B., \& Parkin, S. S. P. (2009). Generation of local magnetic fields at megahertz rates for the study of domain wall propagation in magnetic nanowires. Applied Physics Letters, 95(26), 2625031/3. [262503]. https://doi.org/10.1063/1.3265738

DOI:

$10.1063 / 1.3265738$

Document status and date:

Published: 01/01/2009

\section{Document Version:}

Publisher's PDF, also known as Version of Record (includes final page, issue and volume numbers)

\section{Please check the document version of this publication:}

- A submitted manuscript is the version of the article upon submission and before peer-review. There can be important differences between the submitted version and the official published version of record. People interested in the research are advised to contact the author for the final version of the publication, or visit the $\mathrm{DOI}$ to the publisher's website.

- The final author version and the galley proof are versions of the publication after peer review.

- The final published version features the final layout of the paper including the volume, issue and page numbers.

Link to publication

\section{General rights}

Copyright and moral rights for the publications made accessible in the public portal are retained by the authors and/or other copyright owners and it is a condition of accessing publications that users recognise and abide by the legal requirements associated with these rights.

- Users may download and print one copy of any publication from the public portal for the purpose of private study or research.

- You may not further distribute the material or use it for any profit-making activity or commercial gain

- You may freely distribute the URL identifying the publication in the public portal.

If the publication is distributed under the terms of Article 25fa of the Dutch Copyright Act, indicated by the "Taverne" license above, please follow below link for the End User Agreement:

www.tue.nl/taverne

Take down policy

If you believe that this document breaches copyright please contact us at:

openaccess@tue.nl

providing details and we will investigate your claim. 


\title{
Generation of local magnetic fields at megahertz rates for the study of domain wall propagation in magnetic nanowires
}

\author{
Bastiaan Bergman, ${ }^{1}$ Rai Moriya, ${ }^{1}$ Masamitsu Hayashi, ${ }^{1}$ Luc Thomas, ${ }^{1}$ Christy Tyberg, ${ }^{2}$ \\ Yu Lu, ${ }^{2}$ Eric Joseph, ${ }^{2}$ Mary-Beth Rothwell, ${ }^{2}$ John Hummel, ${ }^{2}$ William J. Gallagher, ${ }^{2}$ \\ Bert Koopmans, ${ }^{3}$ and Stuart S. P. Parkin ${ }^{1, a)}$ \\ ${ }^{1}$ IBM Almaden Research Center, San Jose, California 95210, USA \\ ${ }^{2}$ IBM T. J. Watson Research Center, Yorktown Heights, New York 10562, USA \\ ${ }^{3}$ Department of Applied Physics, Eindhoven University of Technology, 5600 MB Eindhoven, \\ The Netherlands
}

(Received 31 March 2009; accepted 30 August 2009; published online 28 December 2009)

\begin{abstract}
We describe a technique for generating local magnetic fields at megahertz rates along magnetic nanowires. Local and global magnetic fields are generated from buried copper fine-pitch wires fabricated on $200 \mathrm{~mm}$ silicon wafers using standard complementary metal-oxide-semiconductor back-end process technology. In combination with pump-probe scanning Kerr microscopy, we measure the static and dynamic propagation fields of domain walls in permalloy nanowires. () 2009 American Institute of Physics. [doi:10.1063/1.3265738]
\end{abstract}

The creation and manipulation of magnetic domain walls (DWs) in magnetic nanowires form the basis of several recently proposed memory and logic devices. ${ }^{1-4}$ This has stimulated considerable research into the field and current driven magnetization dynamics of DWs in nanowire devices. ${ }^{5-7}$ Various techniques have been used to probe the dynamics of DWs including quasistatic techniques, such as magnetic force microscopy ${ }^{2,8}$ and photoemission electron microscopy, ${ }^{9}$ as well as real time techniques including anisotropic magnetoresistance (AMR), ${ }^{10}$ magnetic scanning transmission X-ray microscopy, ${ }^{11}$ and magneto-optic Kerr effect (MOKE). ${ }^{12,13}$

Among these techniques MOKE is a particularly powerful means of measuring local magnetization distributions in magnetic materials without perturbing their magnetic structure. ${ }^{14}$ To use MOKE to study magnetization dynamics, it is typically required that the experiment be repeated many times (perhaps $\sim 10^{5}-10^{6}$ ) to achieve sufficient signal to noise. Since measurements of DW dynamics often require the use of magnetic fields, it would be highly useful to generate magnetic fields at high repetition rates. Conventional electromagnets are too slow due to their large inductance. In this letter, we demonstrate the fabrication and use of chiplets with two levels of copper fine-pitch wiring, which can generate large local (up to $\sim 400 \mathrm{Oe}$ ) and global magnetic fields (up to $\sim 50 \mathrm{Oe}$ ) at megahertz repetition rates.

The chiplets were fabricated using complementary metal-oxide-semiconductor wiring interconnect processes on $200 \mathrm{~mm}$ diameter silicon wafers. ${ }^{15}$ Using a standard damascene process ${ }^{16}$ with a $248 \mathrm{~nm}$ optical stepper, highly conductive $(2-3 \mu \Omega \mathrm{cm})$, dense (1:1 line and spacing), and small aspect ratio (almost 1:1) copper lines, as narrow as $200 \mathrm{~nm}$ wide, are buried in $\mathrm{SiO}_{2}$ insulator. Two levels of copper lines (labeled M1 and M2) are fabricated by the following sequence: (1) chemical vapor deposition of $\mathrm{SiO}_{2},(2)$ optical lithography and reactive ion etching of the trench, (3) filling the trench with $\mathrm{Ta} / \mathrm{TaN}$ liner and $\mathrm{Cu}$ seed layer and overfilling with electroplated $\mathrm{Cu}$, and (4) chemical mechani-

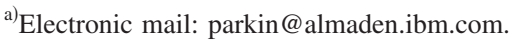

cal polishing of $\mathrm{Cu}$ and liner to complete the trench processing. To obtain an extremely flat surface, an extra thick $\mathrm{SiCHN}$ layer is added after the second $\mathrm{Cu}$ level (M2) and is smoothed by a chemical mechanical polishing (CMP) planarization process. The resulting surface was very smooth with a root mean square roughness of a few angstroms. This is critical for the subsequent fabrication of the magnetic nanowires.

The silicon wafers with the completed copper wiring were laser diced into 1 in. square chiplets, each containing approximately 100 devices. In this letter, we discuss results obtained by patterning with electron beam lithography and argon ion milling, on $300 \mathrm{~nm}$ wide, $22 \mathrm{~nm}$ thick permalloy $\left(\mathrm{Ni}_{80} \mathrm{Fe}_{20}\right)$ nanowires. Figure 1 shows a cross-sectional diagram of the completed device (a), an optical image of the top of the device (b), and a cross-section scanning electron microscope image of part of the device (c). The lower M1 level includes wide copper lines $[\sim 35 \mu \mathrm{m}$ wide in the device shown in Fig. 1(b)], which are $400 \mathrm{~nm}$ thick. These are used to generate global magnetic fields uniform along the length of the nanowire [0.18 Oe/mA (Ref. 17)]. By contrast the upper M2 copper wiring level (150 nm thick) contains a variety of structures. Many of these include series of parallel copper lines with widths and separations of 200 or $400 \mathrm{~nm}$. These lines are used to generate large, localized, magnetic fields for the purposes of injecting DWs into the magnetic nanowires $(10 \mathrm{Oe} / \mathrm{mA})$. These lines can also be used to provide tunable dynamic pinning sites along the nanowire (not used here). The magnetic nanowires are aligned perpendicular to the M1 and M2 copper lines.

It is important that the vertical separation of the M2 copper wires from the nanowire be as small as possible so as to both maximize the field generated per milliampere passed through the M2 lines and to provide a sharper field profile. This requires the thinnest possible insulating layer above M2. The use of SiCHN allowed for thinner such layers.

The DW dynamics of the fabricated permalloy nanowires ${ }^{18}$ were studied using a pump-probe MOKE technique. Here the "pump" consists of a series of synchronized field pulses generated by passing current pulses through sev- 
(a)

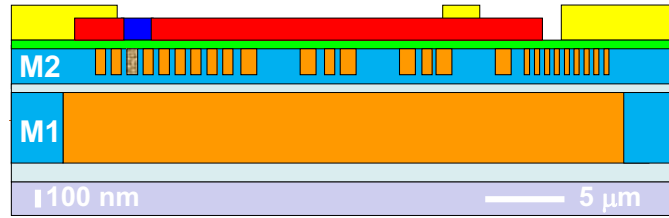

(b)

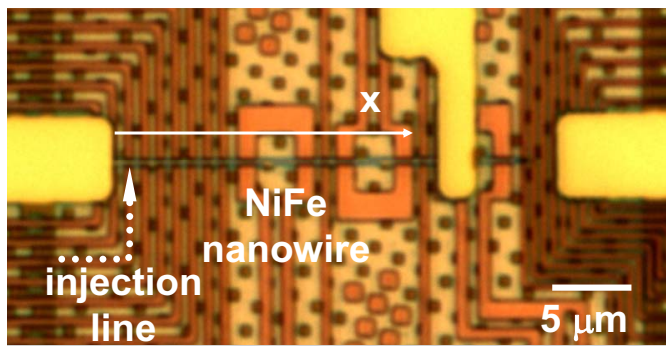

(c)

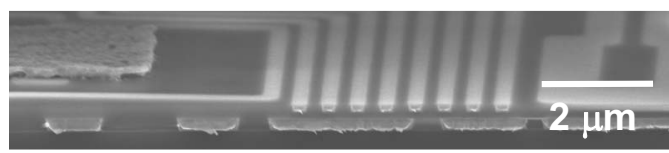

FIG. 1. (Color online) (a) Schematic cross section of the device showing two levels of copper wiring layers labeled as M1 and M2 (dark and pale blue rectangles are $\mathrm{SiO}_{2}$ ). The cross-section of the $\mathrm{Cu}$ lines are shown as rectangles (orange). An SiCHN (N-Blok) dielectric layer (green rectangle) is used on top of M2 to create an ultra smooth surface on which the permalloy nanowires are fabricated. A nanowire is shown as a rectangular shape (red) on top of the SiCHN layer. The darker rectangle within the nanowire (dark blue) represents a magnetic domain. The copper lines are oriented at $90^{\circ}$ to the length of the permalloy nanowire so that the fields generated by these lines are oriented along the nanowire. (b) The $\mathrm{Cu}$ lines can be seen in this optical image of the top side of the device through the thin N-Blok layer. The M1 line and the M2 lines (with various widths) in this particular device are drawn in (a) for guidance. Note that also shown in this device are copper loops for detection of inductive voltage signals. The CMP process requires even fill with metal and dielectric: the arrays of copper dots seen in the image are fabricated for this purpose. On top of the N-Blok layer are the permalloy nanowire (300 nm wide) and three electrical contact pads (only the left 2 are used here). (c) A high resolution cross-section scanning electron micrograph of part of a chiplet. Horizontal and vertical scales are shown at the bottom of the figure.

eral of the buried $\mathrm{Cu}$ lines. The component of the magnetization along the nanowire $\mathrm{M}_{\mathrm{x}}$ normalized to the saturation magnetization of the nanowire $\mathrm{M}_{\mathrm{S}}$ was probed by its Kerr signal as measured using a pulsed laser diode (440 nm wavelength; $40 \mathrm{ps}$ long, $\sim 87 \mathrm{pJ}$ pulses). After passing through a calcite crystal polarizer, a high numerical aperture (NA $=0.70)$ objective lens was used to focus the laser beam to a $\sim 400 \mathrm{~nm}$ diameter circular spot on the nanowire. The beam is incident perpendicularly on the objective lens and after reflection from the nanowire is recollimated by the same lens. A beam splitter is used to deflect the reflected beam to an analyzer and quadrant diode detector (allowing for measurement of all three magnetization components ${ }^{19,20}$ ). An electronic delay generator was used to vary the delay between the pump and probe from 0 to $1200 \mathrm{~ns}$.

A detailed description of a single pump-probe cycle (repeated at $781 \mathrm{kHz}$ ) will now be given with reference to Figs. 2(a)-2(c). The nanowire is initially fully magnetized to the left so that $M_{x}=-M_{S}$. A current pulse ${ }^{21}$ through the M2 injection line [shown in Fig. 1(b)] is then applied to generate a local field of +260 Oe [Fig. 2(a)] that is large enough to nucleate a domain of reversed magnetization in the nanowire (corresponding to two DWs $\sim 2 \mu \mathrm{m}$ apart-from MOKE measurements). Simultaneously, a current through the M1 line generates a global driving field $\mathrm{H}_{\mathrm{D}}$ along the nanowire

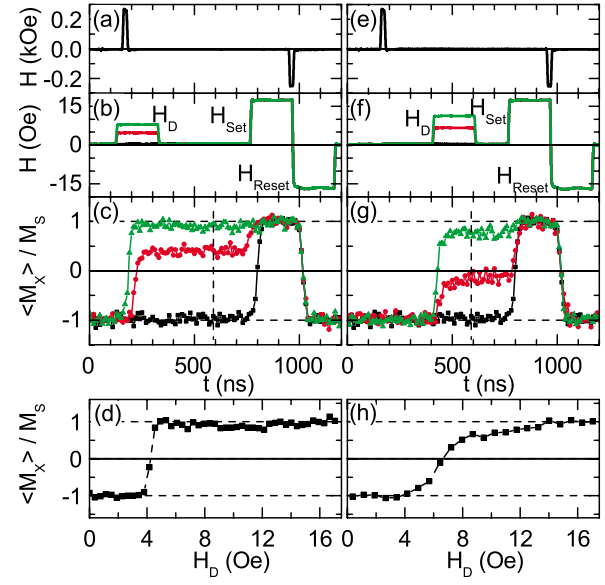

FIG. 2. (Color online) [(a) and (e)] Time evolution of the DW injection field generated by M2 [the particular M2 line is indicated in Fig. 1(b)]. [(b) and (f)] Sequence of global fields generated by M1 used to drive the DW $\left(\mathrm{H}_{\mathrm{D}}\right)$ and to set/reset the magnetization of the nanowire $\left(\mathrm{H}_{\text {set }}\right.$ and $\left.\mathrm{H}_{\text {reset }}\right)$. [(c) and (g)] Time evolution of $\left\langle\mathrm{M}_{\mathrm{x}}\right\rangle / \mathrm{M}_{\mathrm{s}}$ at $\mathrm{x}=8.5 \mu \mathrm{m}$. [(d) and (h)] Dependence of $\left\langle\mathrm{M}_{\mathrm{x}}\right\rangle / \mathrm{M}_{\mathrm{s}}$ at $\mathrm{x}=8.5 \mu \mathrm{m}$ and at $\mathrm{t}=590 \mathrm{~ns}$ versus $\mathrm{H}_{\mathrm{D}}$. (a)-(d) correspond to dynamic propagation of the DW in which $\mathrm{H}_{\mathrm{D}}$ is applied during the DW injection, whereas (e)-(h) correspond to static propagation of the DW in which $H_{D}$ is applied $230 \mathrm{~ns}$ after the DW injection pulse is completed. $\mathrm{H}_{\mathrm{D}}$ $=0$ Oe (black lower curve), 4.4 Oe (red middle curve), and 7.6 Oe (green upper curve) in (a)-(d), 0 Oe (black lower curve), 6.7 Oe (red middle curve) and $11 \mathrm{Oe}$ (green upper curve) in (e)-(h).

[Fig. 2(b)]. This causes the injected DW to move toward the right end of the nanowire. This pulse is made sufficiently long (200 ns) to allow the DW to propagate along the entire length of the nanowire (if $\mathrm{H}_{\mathrm{D}}$ exceeds the propagation field). At some later time (here $\mathrm{t}=760 \mathrm{~ns}$ ) a large field pulse $\mathrm{H}_{\text {set }}$ generated by $\mathrm{M} 1$ ensures the injected DW propagates to the end of the nanowire if it has not already done so. This allows for normalization of the measured Kerr rotation to that corresponding to $\mathrm{M}_{\mathrm{S}}$. The final step is to reset the magnetic state of the nanowire back to its initial fully magnetized condition using negative field pulses from both M1 and M2 [see the pulses at $\mathrm{t}=900 \mathrm{~ns}$ in Figs. 1(a) and 1(b)]. This field sequence is repeated $\sim 10^{6}$ times to obtain adequate signal to noise in the Kerr signal which is measured using a lock-in technique. ${ }^{22}$ Thus, the average value of the normalized component of the magnetization along $\mathrm{x},\left\langle\mathrm{M}_{\mathrm{x}}\right\rangle / \mathrm{M}_{\mathrm{S}}$ is found.

Figure 2(c) shows the temporal evolution of $\left\langle\mathrm{M}_{\mathrm{x}}\right\rangle / \mathrm{M}_{\mathrm{S}}$ measured at $x=8.5 \mu \mathrm{m}$ for three different values of $\mathrm{H}_{\mathrm{D}}$. When $\mathrm{H}_{\mathrm{D}}=7.6 \mathrm{Oe}$, the DW reaches this point shortly after injection so that $\left\langle\mathrm{M}_{\mathrm{x}}\right\rangle / \mathrm{M}_{\mathrm{S}}$ changes rapidly from $-\mathrm{M}_{\mathrm{S}}$ to $+\mathrm{M}_{\mathrm{S}}$. However, when $\mathrm{H}_{\mathrm{D}}=4.4 \mathrm{Oe}$, the DW takes slightly longer to reach the measurement location, but, more importantly, the magnetization does not switch completely to $+\mathrm{M}_{S}$, but rather attains an intermediate level of only $\sim+0.5 \mathrm{M}_{\mathrm{S}}$. This corresponds to the DW propagating for only a fractional percentage of the repeated pump cycles. Indeed, $\left\langle\mathrm{M}_{\mathrm{x}}\right\rangle / \mathrm{M}_{\mathrm{S}}$ corresponds to the probability that the DW propagated along the nanowire in a given pump cycle for this drive field. When $\mathrm{H}_{\mathrm{D}}=0$ the injected DW remains at its injection point so that $\left\langle\mathrm{M}_{\mathrm{x}}\right\rangle / \mathrm{M}_{\mathrm{S}}=0$ until the set pulse is applied. Note that the value of $\mathrm{H}_{\text {set }}$ was chosen to be sufficiently large that the DWs would always be driven along the nanowire.

The detailed dependence of the probability of DW propagation on the drive field is shown in Fig. 2(d). Clearly no DW propagation takes place below a critical propagation 


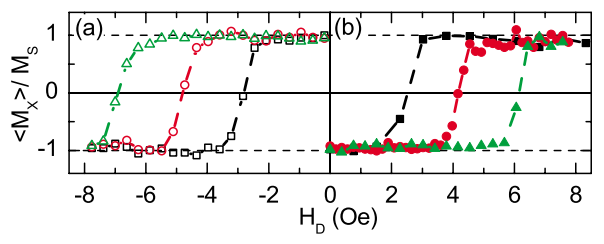

FIG. 3. (Color online) Influence of current on dynamic propagation of DW. $\left\langle\mathrm{M}_{\mathrm{x}}\right\rangle / \mathrm{M}_{\mathrm{s}}$ versus $\mathrm{H}_{\mathrm{D}}$ when $\mathrm{j}=0$ (red open and closed circles), -0.4 $\times 10^{12} \mathrm{~A} \mathrm{~m}^{-2}$ (black open and closed squares) and $+0.4 \times 10^{12} \mathrm{~A} \mathrm{~m}^{-2}$ (green open and closed triangles). The current is simultaneously applied with the drive field. Data are shown for (a) tail to tail DWs (open symbols) and (b) head to head (closed symbols).

field $H_{P}^{D}=4.2 \pm 0.4$ Oe above which $100 \%$ of the DWs propagate. In these measurements, $\mathrm{H}_{\mathrm{D}}$ is applied in concert with the injection field pulse so that the DW does not come to rest after injection if $\mathrm{H}_{\mathrm{D}}>H_{P}^{D}$. This corresponds to a measurement of the dynamic propagation field. The same experiment is repeated in Figs. 2(e)-2(h) except that the DW is allowed to come to rest after injection for $\sim 200 \mathrm{~ns}$ so that the static propagation field can now be measured, i.e., the field required to drive an initially stationary DW along the nanowire.

It is clear from Figs. 2(d) and 2(h) that the propagation field of a moving and a stationary DW are distinctly different. The critical propagation field of the stationary DW ( $\sim 6.5$ Oe for $50 \%$ probability of motion) is significantly larger and the distribution of the propagation fields is also much broader.

It is now well established that spin polarized current can strongly influence the propagation of DWs via the mechanism of transfer of spin angular momentum (SMT) from the current to the DW. ${ }^{2,4,23,24}$ The measurement described in Fig. 2 can be extended to include the role of current. Figures 3(a) and 3(b) show measurements of the dynamic propagation field with and without current applied. A current of 0.4 $\times 10^{12} \mathrm{~A} / \mathrm{m}^{2}$ significantly affects $H_{P}^{D} . H_{P}^{D}$ is increased/ decreased by $\sim 2$ Oe when the flow of spin angular momentum opposes/aids the field driven DW motion. To check that the change in $H_{P}^{D}$ arises from SMT rather than the self-field generated by the current flowing through the nanowire the measurement was carried out for both tail to tail and head to head DWs [Figs. 3(a) and 3(b), respectively]. Our results are consistent with the SMT mechanism, which is independent of the DW type rather than an Oersted field effect which would drive these DWs in opposite directions.

From extrapolation of the data in Fig. 3, current induced DW motion would take place in zero field at a current density of $\sim 0.9 \times 10^{12} \mathrm{~A} / \mathrm{m}^{2}$, consistent with our previous studies using AMR. ${ }^{5,25}$ However, the nanowire was not able to withstand such high current densities because it became too hot. The poor thermal conductivity of the relatively thick dielectric layers used to fabricate the buried $\mathrm{Cu}$ lines results in significant heating of the nanowires.

In summary, we have developed a technique for generating large local magnetic fields at megahertz rates using two levels of copper metal lines buried close to the surface of a silicon wafer. The current pulses that pass through these lines are used to generate magnetic fields locally or globally along magnetic nanowires fabricated on the surface of the patterned wafer. These fields are used to both inject and drive DWs along the nanowires. Using this device, together with a pump-probe MOKE detection scheme, we have demonstrated that the static and dynamic propagation fields of DWs in permalloy nanowires are substantially different.

${ }^{1}$ D. A. Allwood, G. Xiong, C. C. Faulkner, D. Atkinson, D. Petit, and R. P. Cowburn, Science 309, 1688 (2005).

${ }^{2}$ S. S. P. Parkin, M. Hayashi, and L. Thomas, Science 320, 190 (2008).

${ }^{3}$ M. P. Kostylev, A. A. Serga, T. Schneider, B. Leven, and B. Hillebrands, Appl. Phys. Lett. 87, 153501 (2005).

${ }^{4}$ M. Hayashi, L. Thomas, R. Moriya, C. Rettner, and S. S. P. Parkin, Science 320, 209 (2008).

${ }^{5}$ M. Hayashi, L. Thomas, C. Rettner, R. Moriya, Y. B. Bazaliy, and S. S. P. Parkin, Phys. Rev. Lett. 98, 037204 (2007).

${ }^{6}$ L. Thomas, M. Hayashi, X. Jiang, R. Moriya, C. Rettner, and S. S. P. Parkin, Nature 443, 197 (2006).

${ }^{7}$ G. Tatara, H. Kohno, and J. Shibata, Phys. Rep. 468, 213 (2008)

${ }^{8}$ A. Yamaguchi, T. Ono, S. Nasu, K. Miyake, K. Mibu, and T. Shinjo, Phys. Rev. Lett. 92, 077205 (2004).

${ }^{9}$ L. Thomas, C. Rettner, M. Hayashi, M. G. Samant, S. S. P. Parkin, A. Doran, and A. Scholl, Appl. Phys. Lett. 87, 262501 (2005).

${ }^{10}$ M. Hayashi, L. Thomas, C. Rettner, R. Moriya, and S. S. P. Parkin, Nat. Phys. 3, 21 (2007).

${ }^{11}$ G. Meier, M. Bolte, R. Eiselt, B. Kruger, D.-H. Kim, and P. Fischer, Phys. Rev. Lett. 98, 187202 (2007).

${ }^{12}$ G. S. D. Beach, C. Nistor, C. Knutson, M. Tsoi, and J. L. Erskine, Nature Mater. 4, 741 (2005)

${ }^{13}$ R. P. Cowburn, D. A. Allwood, G. Xiong, and M. D. Cooke, J. Appl. Phys. 91, 6949 (2002).

${ }^{14}$ M. R. Freeman and B. C. Choi, Science 294, 1484 (2001).

${ }^{15}$ The chiplets were fabricated in the Microelectronics Research Laboratory, IBM T.J. Watson Research Center.

${ }^{16}$ R. Rosenberg, D. C. Edelstein, C.-K. Hu, and K. P. Rodbell, Annu. Rev. Mater. Sci. 30, 229 (2000).

${ }^{17}$ Fields generated by the M1 and M2 lines are calculated values in the middle of the nanowire. The M1 fields were experimentally verified by comparing the dynamic propagation fields measured using M1 field and an externally applied field.

${ }^{18} \mathrm{The}$ nanowire structure is composed of $0.5 \mathrm{Fe} / 0.3 \mathrm{Al} / 10 \mathrm{Al}_{2} \mathrm{O}_{3} / 22 \mathrm{NiFe} /$ $0.9 \mathrm{Cu} / 4.9 \mathrm{Pt}$ (thicknesses in $\mathrm{nm}$ ).

${ }^{19}$ C. D. Wright, W. W. Clegg, A. Boudjemline, and N. A. E. Heyes, Jpn. J. Appl. Phys., 33, 2058 (1994).

${ }^{20}$ C. Jozsa, J. H. H. Rietjens, M. v. Kampen, E. Smalbrugge, M. K. Smit, W. J. M. de Jonge, and B. Koopmans, J. Appl. Phys. 95, 7447 (2004).

${ }^{21}$ The current pulse length at half amplitude is $20 \mathrm{~ns}$. The rise and fall times are $4.5 \mathrm{~ns}$

${ }^{22}$ The reference signal from the lockin amplifier is used to gate the M2 injection pulse at a frequency of $1.1 \mathrm{kHz}$ with a time constant of $300 \mathrm{~ms}$

${ }^{23}$ J. C. Slonczewski, J. Magn. Magn. Mater. 159, L1 (1996).

${ }^{24}$ M. Hayashi, L. Thomas, Y. B. Bazaliy, C. Rettner, R. Moriya, X. Jiang, and S. S. P. Parkin, Phys. Rev. Lett. 96, 197207 (2006).

${ }^{25}$ M. Hayashi, L. Thomas, C. Rettner, R. Moriya, X. Jiang, and S. S. P. Parkin, Phys. Rev. Lett. 97, 207205 (2006). 